DOI: http://dx.doi.org/10.4995/LC2015.2015.548

\title{
Dattiers Andinos y la Búsqueda Paciente en Rue de Sèvres, 1948-1959 ${ }^{1}$
}

\author{
I. Quintana Guerrero \\ Universidad de São Paulo
}

\begin{abstract}
Resumen: Con la Unidad de Habitación marsellesa, el Atelier Le Corbusier transformaba su personal y métodos. Recurrentemente, se ha denominado a ésta como la fase del Grand Atelier, en cuyo ocaso surgieron nuevos desafios y elementos para un "espacio inefable". De límites imprecisos, esa Búsqueda Paciente implicaba un estado de ánimo transicional que confrontaba a Le Corbusier con sus propios métodos y con algunos de sus colaboradores, a los que peyorativamente atribuyó el apodo de dattiers (datileras), debido a su presunta arrogancia y baja productividad. Este trabajo reconstruye los principales aspectos del paso de algunos colaboradores suramericanos de Le Corbusier por París entre 1948 y 1959. Su participación fue larga e intensa, alcanzando en ocasiones el estatus de coordinadores y abordando obras en todas las escalas. Aún cuando, entre ellos, sólo Augusto Tobito fue directamente calificado como dattier, sus colegas colombianos compartían algo de su rebeldía, autonomía o destreza; de ahi que les hagamos extensivo ese apelativo. Así pretendemos construir un relato que contrarreste las abundantes narrativas sobre proyectos e influencia del franco-suizo en territorio andino.
\end{abstract}

Abstract: With Marseille Housing Unit, the Atelier Le Corbusier began a transformation of its staff and methods. Frequently, this phase is known as Le Grand Atelier, receiving new challenges during its ending, and conceiving new elements for an "ineffable space". With undefined boundaries, the Patient Research involved a transitional frame of mind opposing Le Corbusier to his own proceedings and to some of his collaborators. Pejoratively, the master named them as dattiers (datepalms), due to their alleged arrogance and low productivity. This work reconstructs several aspects of the internship of some South American collaborators on Le Corbusier at Paris between 1948 and 1959. Their participation was extended and intense, allowing them to reach, in some cases, the status of coordinators, and engaging works in all the scales. Even though just Augusto Tobito was directly called as dattier, his Colombian coworkers shared his rebellion, autonomy or skills. That is why we also use that adjective for them. We intend to create a complementary story for plenty of narratives about projects and influences of the French-Swiss architect in the Andes territory.

Palabras clave: Le Corbusier; arquitectos modernos suramericanos; planes urbanos; proyectos de habitación. Keywords: Le Corbusier; South American Modern architects; urban plans; housing project.

\section{Introducción}

El Atelier Le Corbusier tuvo diversos matices durante sus 42 años de existencia, comenzando por los "años heroicos" 2 (previos a la Segunda Guerra Mundial), de camaradería entre un joven arquitecto y sus escasos colaboradores. Debido a la exigüidad de documentos, es difícil establecer la acción de algunos de ellos, cuyo paso por el taller fue breve. Dicha documentación se hizo sistemática ante la cantidad de asalariados y proyectos

\footnotetext{
${ }^{1}$ Trabajo derivado de una investigación doctoral sobre los colaboradores latinoamericanos de Rue de Sèvres durante sus fases. Se confrontaron fuentes primarias como planos, bocetos, correspondencia y entrevistas (consultados, principalmente, en las Fundaciones Le Corbusier (FLC) y Rogelio Salmona, en los archivos de Germán Samper y en las colecciones especiales de Frances Loeb Library - Harvard University), con publicaciones sobre cada uno de los actores; disertaciones y tesis doctorales sustentadas durante los últimos 10 años, así como algunas obras que abordan la metodología de trabajo en el Atelier.

${ }^{2}$ Sterken, Sven: Iannis Xenakis: architecte et ingénieur. Dirección: Bart Verschaffel. Tesis doctoral. Universiteit Gent, 2004.
} 
abordados, número nuevamente reducido durante la que el propio Corbusier llamó como Étape 72 (su edad en 1959, comienzo de esta etapa).

El clímax del taller, en cuanto a cantidad de encargos y obras ejecutadas, acaeció entre ambas instancias. Gracias a proyectos de la postguerra -reconstrucción urbana y viviendas masivas- el taller superó los cien miembros; de ahí su denominación como Grand Atelier. La consagración de "Corbu” como figura mundial atrajo candidaturas de jóvenes abiertos a cualquier condición laboral de con tal de obtener un lugar en el estudio de arquitectura más célebre entonces. La complejidad en sus operaciones, asumiendo paralelamente los estudios técnicos para Marsella y otras obras a través de un órgano adjunto, el ATBAT (Atelier des Bâtisseurs), incitó tácitamente el establecimiento de jerarquías y, por ende, de inevitables roses del maestro con quienes alcanzaron relevancia al interior del equipo. No obstante, la alta rotación de mano de obra y el paso ineludible de los meses suscitaron fluctuaciones del Grand Atelier.

Como hilo conductor subyace la idea de Búsqueda Paciente, con la que "Corbu" designó su taller casi desde sus comienzos, y que en ocasiones ha sido identificada con el ocaso de su carrera y la materialización de un "espacio inefable" y de un lenguaje brutalista. Esa búsqueda también estaría vinculada a un état d'âme, cuestionando certezas cultivadas durante las últimas décadas. La presencia de colaboradores más maduros, curtidos en los procedimientos lecorbusierianos e incluso tan temperamentales como su jefe, contribuyó a este aspecto. A tres de ellos, Xenakis, Maisonnier y Tobito, atribuyó el apelativo de dattiers royaux ${ }^{3}$ (datileras reales), y apartó de su servicio, sin previo aviso, luego del verano de 1959.

Tobito, venezolano, se recibió como arquitecto en Bogotá, donde construyó sus primeras obras y conoció a Le Corbusier. Menos divulgado que el impacto del viaje sobre el imaginario lecorbusieriano ha sido el paso del venezolano, junto al de cuatro colombianos, por el taller; hecho sorprendente si se considera que dos de ellos, Rogelio Salmona y Germán Samper, tuvieron colaboraciones prolongadas en Rue de Sèvres, con carácter y desempeño equiparables a los de los dattiers.

\section{Rogelio Salmona (París, 1927 - Bogotá, 2007)}

Primer colaborador andino, le petit Salmoná (como le llamaban sus colegas) conoció al maestro durante su primera visita a Bogotá, en 1947, como su traductor oficial y anfitrión en una cena ofrecida por su padre. Fue entonces cuando "Corbu" mencionó que sólo en su taller era posible aprender arquitectura y que allí esperaba a Roger. Con apenas 20 años y tres semestres en la Universidad Nacional, éste debió regresar a París, tras la revuelta popular que azotó a Bogotá en abril de 1948. Ya en Rue de Sèvres, fue rechazado por Le Corbusier, quien ni siquiera recordaba a su padre. El joven se impondría en una primera disputa, al hacerse contratar como gratteur (pasante sin pago), abandonando la École des Beaux Arts, donde estaba inscrito. En compensación, hizo cursos de sociología del Arte con Pierre Francastel, motivando su paulatino alejamiento ideológico del maestro.

Los seis años y tres meses del franco-colombiano en el taller atañen 29 proyectos, organizados en tres ejes temáticos: vivienda social masiva y planes de reconstrucción urbana; casas individuales para élites y algunos proyectos para Chandigarh ${ }^{4}$.

\footnotetext{
${ }^{3}$ « $[\ldots]$ chacun de vous est un dattier royal ! // [...] c'est l'eau et le soleil qui ont le dessus. // Leur destin est d'être là, toujours présents. // Mais on les engueule toujours : ce soleil est trop chaud, cette pluie mouille ». Nota de 11/07/1957 (FLC U3-8-207).

${ }^{4}$ En este documento apenas incluimos tres imágenes seleccionadas entre el vasto material que sustenta los relatos. En el caso de los planos, proporcionamos códigos de algunos de ellos, atribuidos por la FLC, para su consulta abierta tanto en esa institución como en la colección de DVDs Le Corbusier: Plans (Paris: CodexImages International, 2005). La sigla FGJF
} 


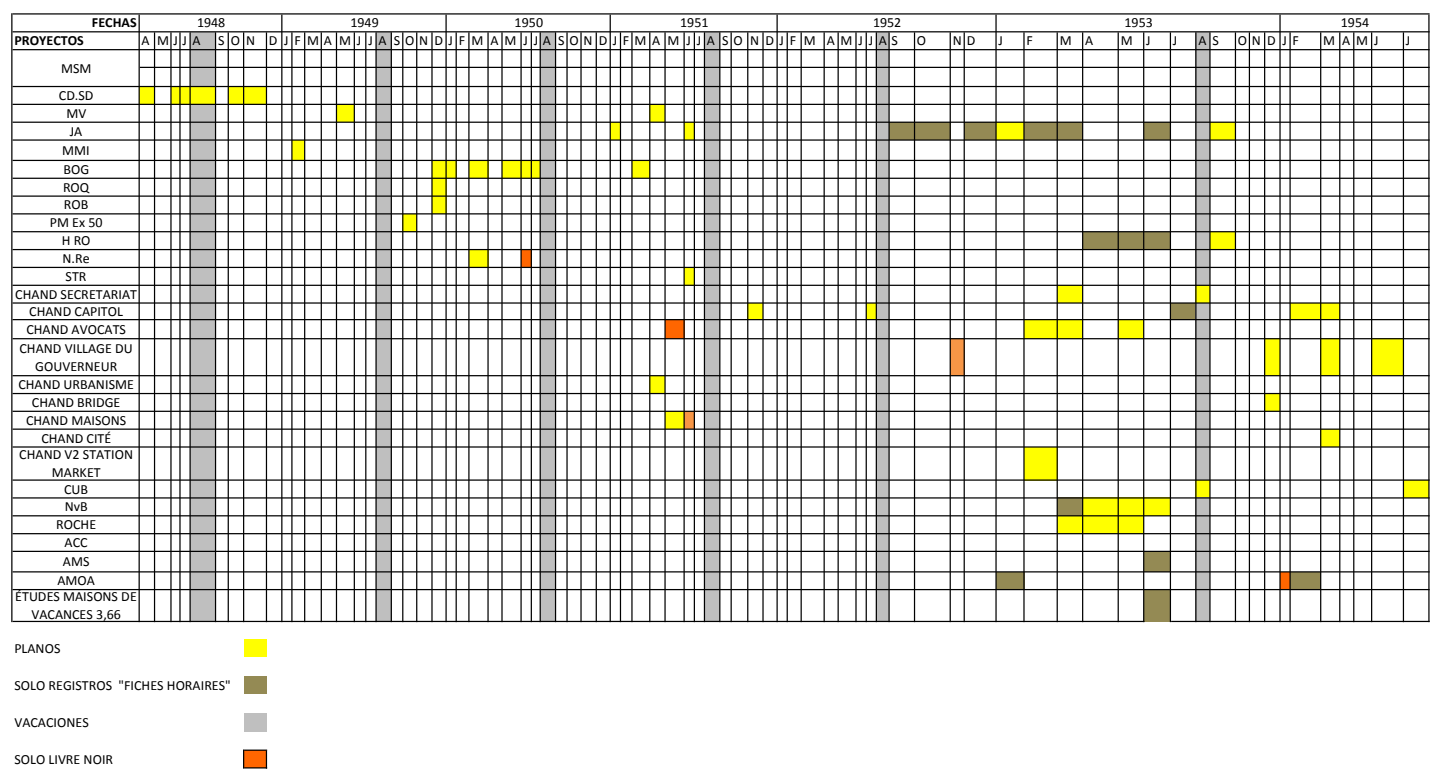

1. Tabla de proyectos lecorbusierianos con documentación relativa a Rogelio Salmona. Fuente: La autora, basada en archivos de la FLC.

\subsection{Laboratorios HBM}

La Unidad de Marsella (MMI) fue ejecutada por el ATBAT, con contribuciones esporádicas de Salmona, quien, junto con Samper y Justino Serralta, visitó la construcción en 1949 y 1950. Los colombianos participaron en otros proyectos urbanos: Marseille Veyre (MV) y Marseille-Sud-Michelet (MSM; colina que ilustraron en una perspectiva aérea - FLC 23110). En el segundo (FLC 30202) habría un anillo verde para recreación, circundado por bloques à redent $\mathrm{y}$ vivienda de baja densidad, apelando a las tres joies essentielles a la vida urbana divulgadas en los CIAM (a cuya sexta versión asistieron los colegas): luz, espacio y verdor.

La creación de Habitations Bon Marché (HBM) no era solamente una prioridad del estado francés sino de cooperativas privadas. Una de ellas solicitó al franco-suizo una unidad para Rezé-les-Nantes (NRe), en 1951 (FLC 01519). De menor presupuesto que su antecesora, su plano de implantación fue hecho por Salmona, quien, paralelamente, ejecutó varias planchas de las unités para un barrio de 800 viviendas en Estrasburgo, Rotterdam (STR). Reinaldo Valencia (Quibdó, 1922 - Chalonnes-sur-Loire, 1994), colombiano que llegó al atelier 16 meses después que Roger, permaneciendo otros 20 meses, dibujó las plantas generales del conjunto, con sus sistemas hidráulico y eléctrico (FLC 30667A; FLC 30708). Vale la pena abrir un paréntesis para comentar que Valencia había contribuido más que sus compatriotas en el desarrollo de la Unidad marsellesa, especialmente en el estudio de policromía de las fachadas (febrero de 1951; FLC 25643 - FLC 25646).

\subsubsection{LC BOG}

Rotterdam se benefició del Plan Regulador de Bogotá. Sin ánimo de ahondar en ese proyecto, vale la pena mencionarlo como tentativa gubernamental de planear esa capital a futuro y reconstruir su centro histórico, devastado en abril de 1948. Junto a otros miembros del taller como Carlos Clémot (Uruguayo) y Valencia (que

corresponde al fondo Guillermo Jullian de la Universidad Católica de Chile (Centro de Originales Sergio Larraín GarcíaMoreno), mientras que IFA corresponde al archivo de Arquitectura Moderna del Institut Français d'Architecture y GS al archivo personal de Germán Samper. 
trabajó específicamente con Salmona en el estudio de densidades), Roger elaboró el Informe Técnico, presentado en Septiembre de 1950 bajo el formato de la Grilla CIAM, con base en el protocolo elaborado por Le Corbusier y las autoridades colombianas en Roquebrune-Cap-Martin (agosto de 1949). A pesar de su desacuerdo, Salmona dibujó axonometrías del Centro Cívico (FLC 31561), que conservaría escasos inmuebles y acogería nuevas unités y edificios ministeriales, en el marco de la Plaza Principal. Con Samper, trazó borradores para la implementación del sistema de las 7 vías, mas calles peatonales (FLC 33686) ${ }^{5}$.

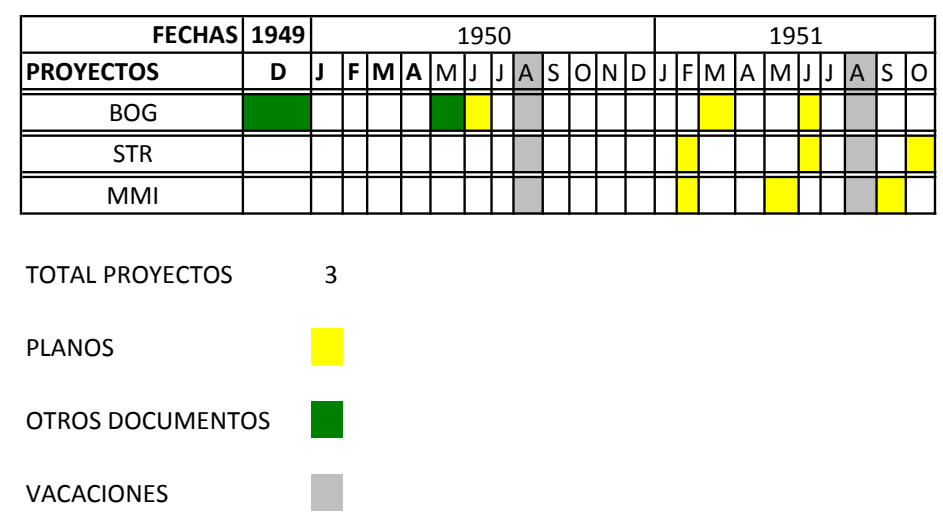

2. Tabla de proyectos lecorbusierianos con documentación relativa a Reinaldo Valencia. Fuente: La autora, basada en archivos de la FLC.

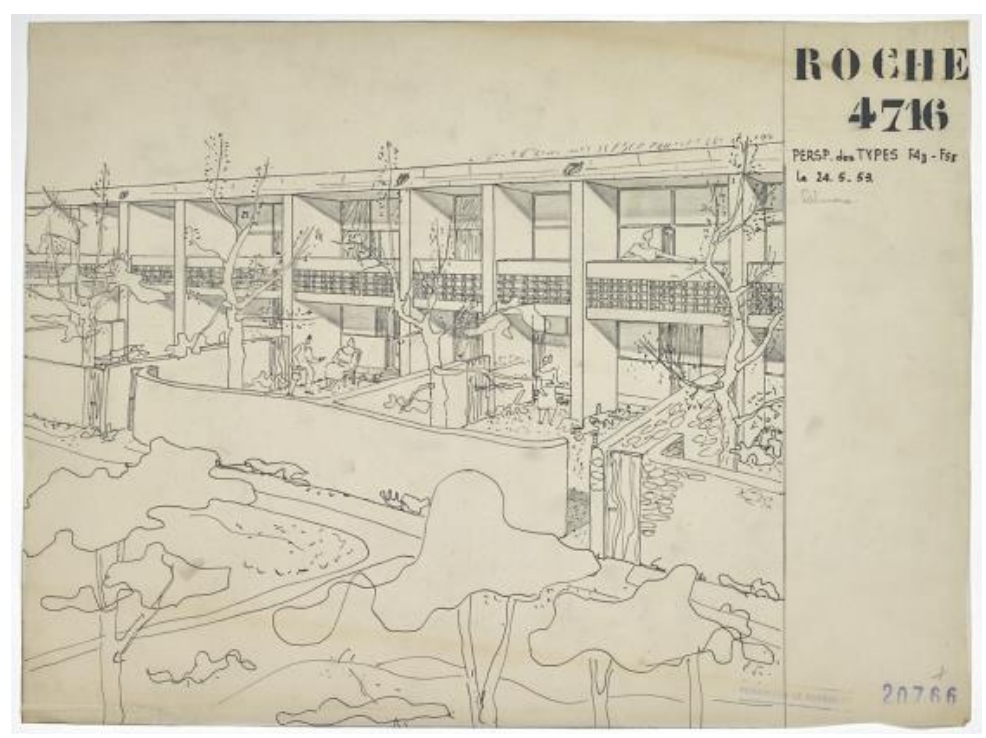

3. Plano $N^{o}$. 4716: perspectiva casas tipo La Rochelle en La Citadelle. Fuente: FLC (20766).

\footnotetext{
${ }^{5}$ Según Salmona, él propuso un octavo tipo de vía, exclusivo para bicicletas, inspirado en ciclorrutas de Ámsterdam. Tarchópulos, Doris: Las Huellas del Plan para Bogotá de Le Corbusier, Sert y Wiener. Dirección: Joaquín Sabaté, José María Ezquiaga. Tesis doctoral. Universitat Politécnica de Catalunya, 2010, p. 138.
} 


\subsubsection{Barrios experimentales}

En junio de 1953, Roger contribuyó a un proyecto experimental para Roubaix: HEM (HRo), donde se implementarían, entre varias alternativas, casas tipo La Rochelle (usadas en Bogotá), de dos pisos y cubiertas inclinadas, basadas en las "mesopotamiens" lecorbusierianas de 1939. Allí también se concibió una nueva tipología: Rez-de-chaussée, resuelta en una única planta, de $81.65 \mathrm{~m}^{2}$ (FLC 20829). La Citadelle (ROCHE), proyecto sin lote determinado, evolucionaba el esquema La Rochelle (FLC 20762); en él, perspectivas internas de Salmona recrean sus condiciones espaciales, semejantes a las de las células en las unités (Fig. 3). Idénticas imágenes se usaron para Neuve-Ville-Briey (NvB), nuevo suburbio de la ciudad minera de Briey (IFA/PINGU/C/53), proyectado por Georges-Henri Pinguisson, quien invitó a Le Corbusier a construir una Unité (BrF). Su propuesta, de abril de 1953, incorporaba otras unidades de 12 y 17 pisos y un grupo de casas La Rochelle, con plantas y cortes del franco-colombiano (FLC 20770).

\subsection{Casas individuales}

En Chandigarh, Le Corbusier había propuesto un tipo de casa para peones, dibujado por Salmona y eventualmente por Tobito $^{6}$, además de las residencias para funcionarios de más alto rango mencionadas más adelante. A diferencia de éstas, donde se privilegiarían las técnicas de construcción manual locales, la maison du péon estaría cubierta por un sistema mixto, con bóvedas prefabricadas de concreto apoyadas en muros de mampostería (FLC 29113). Con contribuciones menores de Salmona, “Corbu”también compuso tres casas en Ahmedabad (FLC 30244; FLC 06426B). Dos de ellas, Sarabhai (AMS) y Shodhan (ASH), seguían líneas enunciadas por "Corbu" y derivadas de los prototipos Citrohän ("masculino") y Monol ("femenino"). El segundo caso apela nuevamente a la bóveda como elemento distintivo del espacio doméstico lecorbusieriano, luego adoptado en la propia arquitectura de Salmona.

En noviembre de 1949, Roger y Samper desarrollaban un conjunto de casas vacacionales en Roquebrune-CapMartin, Roq et Rob. Se contemplaron varias posibilidades para su construcción (no ocurrida), como un sistema estructural metálico, llamado 2.26 × 2.26 × 2.26 (dimensión básica del Modulor) o Le Brevet. El partido básico de las diferentes de casas Roq y Rob era muy similar al de La Rochelle (células alargadas), también con tres niveles, aunque escalonados, obedeciendo a la accidentada topografía (FLC 18667- FLC 18676). Una serie de perspectivas elaboradas por el dúo colombiano evidencia las bóvedas de concreto como sistema para las cubiertas (FLC 18758). Poco tiempo después (junio de 1951), la familia Jaoul encargaría a "Corbu" dos casas en Neuilly-sur-Seine. Mientras Samper estudió la implantación de las casas, Salmona elaboró parte de los planos de ejecución, junto a Kim y Sachi, en marzo de 1953. Roger también supervisó dibujos de un cuarto colombiano en el taller, cuya estada (de apenas seis meses) aun resulta misteriosa: Alberto Peña.

A diferencia de las casas Roq et Rob, en las Jaoul las bóvedas rebajadas parten de una hoja de piezas cerámicas planas (rasilla) fijadas con yeso, recubierta con una pequeña lámina de concreto - solución calculada por el ingeniero Domenec Escorsa (FLC 09956) tras la visita de Le Corbusier a la casa que Francisco Pizano construyó para su padre en Bogotá, apelando a una solución de naturaleza semejante para la escalera. Los primeros croquis de las fachadas también muestran la disposición pareada de las casas, rápidamente substituida por un esquema en "L” de Samper (FLC 10365). Luego del regreso a Colombia de éste, en 1953, Salmona permaneció 9 meses más junto al maestro, contribuyendo para algunas casas de funcionarios de alto nivel en la Aldea del Gobernador de

\footnotetext{
${ }^{6}$ Según nota del Carnet J35 (24 de febrero de 1955). De Franclieu, Françoise (Ed.): Le Corbusier: Sketchbooks. New York, Cambridge: MIT Press, 1981. 3v, p. 254.
} 
Chandigarh: secretarios de gobierno y militares (tipo V; FLC 05556), asistentes (tipo X; FLC 29098/99) y empleados senior (tipo XI; FLC 05566/67).

\begin{tabular}{|c|c|c|c|c|c|c|c|c|c|c|c|c|}
\hline FECHAS & & & & 195 & & & & & & 1953 & & \\
\hline PROYECTOS & M & & J & A & $S$ & 0 & \begin{tabular}{|l|l|l|}
$N$ & $D$ \\
\end{tabular} & \begin{tabular}{|l|l|l|l}
$J$ & $F$ \\
\end{tabular} & $M$ & $|\mathrm{~A}| \mathrm{N}$ & \begin{tabular}{l|lll}
$M$ & $J$ & $J$ \\
\end{tabular} & $\mathrm{~J} A \mathrm{~A}$ \\
\hline $\mathrm{JA}$ & & & & & & & & & & & & \\
\hline CHAND CAPITOL & & & & & & & & & & & & \\
\hline $\begin{array}{c}\text { CHAND } \\
\text { SECRÉTARIAT } \\
\end{array}$ & & & & & & & & & & & & \\
\hline CHAND GRILLE & & & 189 & & 98 & 72 & & & & & & \\
\hline N.Re & & 92 & 14 & & & & & & & & & \\
\hline $\mathrm{MMI}$ & & 12 & & & & 27 & & & & & & \\
\hline
\end{tabular}

TOTAL PROYECTOS

6

PLANOS

SOLO REGISTROS "FICHES HORAIRES"

4. Tabla de proyectos con documentación de Rue de Sèvres, relativa a Alberto Peña. Fuente: La autora, basado en archivos de la FLC.

\subsection{Urbanismo en Chandigarh}

Junto con Samper, Salmona fue architecte projetteur de las primeras exploraciones urbanas en Punjab ${ }^{7}$. No todos los lineamientos propuestos fueron acogidos, aunque su recepción por parte de las autoridades locales fue mucho mejor que la del Plan Director de Bogotá, proveyendo elementos para Chandigarh: una grilla cartesiana con rigurosa implementación de la regla de las 7V, privilegiando los rápidos desplazamientos. El 23 de abril de 1951, Salmona trazó plantas y perfiles de algunos tipos de vías, complementando las investigaciones sobre arborización de Samper (FLC 05289). La nueva capital indiana también contaría con un Centro Cívico, lejano del corazón de la ciudad: la Explanada del Capitolio fue parcialmente construida, e incluso alterada después de la muerte de "Corbu". Salmona contribuyó en los perfiles que ilustran de la modificación de la topografía original mediante "colinas artificiales" que dialogan con los Montes Himalaya y con las pintorescas siluetas de los nuevos edificios institucionales ${ }^{8}$ (FLC 05291). De entre ellos, el Secretariado y el anexo de Abogados, dos prismas rectangulares configurando las esquinas opuestas de la explanada, poseen trazos de Roger. Los planos del edificio anexo (febrero y marzo de 1953; FLC 04742 - FLC 04756) muestran 6 oficinas de magistrados junior, dividiendo el edificio en sendos módulos (similar estrategia a la adoptada para el Secretariado). Brisesoleils en la fachada sur y una cubierta suspendida (aunque totalmente plana) recuerdan a la propia Alta Corte; mientras que la fachada norte, de ladrillo, sería ciega, similar a la del Museo de Ahmedabad.

\footnotetext{
7 « Pour mener à bien la construction de Chandigarh, Le Corbusier met en place [...] hiérarchie très stricte des tâches, s'alignant sur les conventions de travail de l'époque : calqueur, dessinateur, projeteur, chef d'exécution, inspecteur des travaux, chef d'études et des travaux, chef d'équipe ». Papillault, Rémi: Chandigarh et Le Corbusier, création d'une ville en Inde 1950-1965. Toulouse: Poïsis, 2011, p. 80.

${ }^{8}$ Salmona hizo una poética descripción de la creación del Capitolio, junto a Le Corbusier, en: Arcila, Claudia Antonia: Tríptico Rojo. Conversaciones con Rogelio Salmona. Bogotá: Taurus, 2007, pp. 129-130.
} 


\subsection{La partida de Salmona}

Además de sus discrepancias con el maestro, Salmona consideraba que su experiencia en Rue de Sèvres había sido demasiado teórica. Por eso envió su candidatura a Bernard Zehrfuss, quien proyectaba el CNIT en La Défense. Al ser admitido, presentó su renuncia a "Corbu”. Como regalo de despedida, éste lo invitó a descender al sótano para escoger uno de los cuadros de su autoría. Como un último acto de rebeldía en el taller, el francocolombiano prefirió quedarse con un Juan Gris.

\section{Germán Samper (Bogotá, 1924 - )}

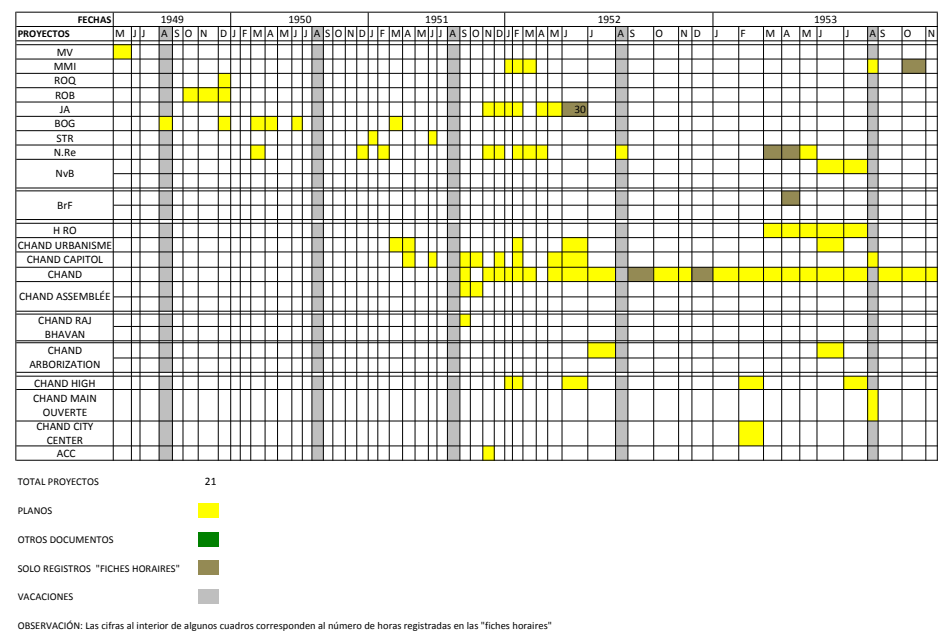

5. Tabla de proyectos lecorbusieriana con documentación relativa a Germán Samper. Fuente: La autora, basada en archivos de la FLC.

Recién graduado de la Universidad Nacional, Samper, con un grupo de estudiantes, recibió al franco-suizo en el aeropuerto de Bogotá, en 1947. Sus conferencias, así como la lectura de sus principales manifiestos, impulsaron al colombiano para postular a una beca del francesa y, en noviembre de 1948, embarcar hacia París. Entonces se presentó espontáneamente al taller, buscando una pasantía no remunerada, inicialmente negada. Mientras tanto, se inscribió en el Instituto Francés de Urbanismo y, como Salmona, en los seminarios de Francastel. Finalmente, gracias a su compatriota y a Georges Candillis, fue reclutado sin que el maestro lo supiese, para elaborar algunas grillas del Plan La Rochelle-Pallice, presentadas en el sexto CIAM.

Consagrado dibujante, Samper recorrió y esbozó proyectos lecorbusierianos en Île-de-France mientras esperaba una oportunidad con "Corbu"; una práctica común entre sus admiradores. Sin embargo, la interacción directa con él y el cambio de lenguaje en los nuevos encargos del taller harían cambiar la concepción idílica de Samper, quien fue llamado por su patrón como Lion, mientras que, por su astucia, Salmona recibió el apodo de Gazelle. Esto denotaba una relación mucho más próxima entre Le Corbusier y Samper; de hecho, la designación del segundo como dessinateur se dio rápidamente.

\subsection{Algunos proyectos urbanos}

Además de los planes para Marsella, Samper también contribuyó al barrio Rotterdam con plantas del complejo (FLC 30663/64); elevaciones y detalles de su unité (FLC 30665/66). Aunque su poder de decisión fue menor para el Plan Director de Bogotá, Samper registró minuciosamente cada una de sus fases en su cuaderno, abordando el estadio previo de la ciudad y la necesidad de fortalecer sus nodos de intercambio comercial y 
conexiones internacionales aéreas, conforme a los Tres Establecimientos Humanos. Un segundo cuaderno contiene borradores del Informe Técnico y de estudios de densidades (se esperaba aumentar, en promedio, a 4600 habitantes por hectárea en el área urbana); distribución de las cuatro funciones urbanas a lo largo de la capital y de las unidades barriales (barras intercaladas y articuladas por una vía vehicular), con un centro de servicios. Finalmente, esbozó casas longitudinales “Gaitán”, inspiradas en los lotissement Barcelona y en Roq et $R o b$, y firmó planos relativos a las intersecciones viarias, dentro de la regla de las $7 \mathrm{~V}$.

\subsubsection{Viviendas en la reconstrucción}

La acción de Samper para la unidad marsellesa fue mucho mayor que la de Salmona, concentrada en una serie de planchas ATBAT, del primer trimestre de 1952 (plantas de los niveles 4, 7 y 8 - FLC 25313/14; detalles de bancos, ventanas y divisiones en la guardería - FLC 25806, FLC 30762). En sus visitas a la obra, el colombiano la registró externa e internamente, con colores y dimensiones detalladas del mobiliario doméstico. Este aprendizaje fue útil en la contribución de Samper para Rezé (1952), también enfocada en detalles constructivos. Junto al panameño Efraín Pérez Chanis, estudió de las diferentes tipologías de apartamentos, especificadas tanto en las plantas tipo como en minúsculas axonometrías (desde $76 \mathrm{~m}^{2}$, células no "traversantes"; FLC 02167); secciones de la caja sur de circulaciones verticales (FLC 02144); planos del sistema hidráulico (FLC 01510; FLC 01687) y estudios para la fachada principal (FLC 02145).

Junto a salmona, Samper también desarrolló las casas Rez-de-Chaussée para Neuve-Ville-Briey, supervisando los planos de Sachi para los subtipos F3 y F5, en escala 1:50, basados en sus propios croquis. Las planchas $\mathrm{N}^{\circ}$. $4739^{9}$ (FLC 20818B); 4742 (FLC 20821B); 4743 (corte, FLC 20822B) y 4740 (FLC 20819B) se repiten en Roubaix. Otros dibujos del dossier HEM fueron firmados por Samper en Marzo de 1953, representando las conexiones viales y topografía de la conurbación Lille-Roubaix-Tourcoing (FLC 20900/03), así como la distribución de zonas verdes y cuerpos de agua dentro de la urbanización (FLC 20914). Una localización dibujada posteriormente por Samper se muestra más densa que la propuesta inicial (FLC 20817).

\subsubsection{El aprendizaje de Jaoul}

Además de las planchas oficiales firmadas junto a Salmona, Samper elaboró un "Estudio de normalización de las casas alargadas" para Roq et Rob: páginas sueltas con esquemas del "volumen alveolar habitable", ceñido a los patrones del Brevet: materialización de la existenzminimum. El interés del colombiano sobre esa patente estaba en sus posibilidades como medio de construcción masiva.

En lo que se refiere al proyecto para los Jaoul, mencionamos anteriormente la participación de Samper en su primera fase. El pequeño presupuesto, el lote reducido, la dificultad de excavar en el mismo y la estricta normativa urbana obligaron a una alteración importante del programa en noviembre de 1951, aunque persistía la independencia entre las viviendas. Al respecto, estudios para su implantación fueron consignados en su cuaderno GS10, incluyendo croquis del propio Corbusier con diferentes alternativas. Llama la atención aquella desarrollada por Samper en diciembre, con ambas unidades paralelas, separadas por un patio (FLC 10315/19). En ese mismo mes comenzó la investigación para las bóvedas: en las notas del colombiano aparecen cálculos de las vigas y muros de carga que las soportarían. Samper ya participaba de reuniones técnicas con Wogensky para determinar éstas y otras especificaciones (tipos de revestimientos del suelo, sistema de desagües de las cubiertas, juntas de dilatación entre elementos prefabricados, etc.) necesarios para la elaboración de detalles técnicos, a incluir en el "permiso de construcción", de marzo de 1952 (FLC 09896/902). Durante el mes siguiente, elaboró

\footnotetext{
${ }^{9}$ Numeración consecutiva de planos en el Cuaderno de Dibujantes o "Livre Noir”.
} 
curiosas elevaciones internas de la casa $\mathrm{B}$, describiendo la disposición interna de los pan-de-verre (FGJF PLR 025 003). Finalmente, en su cuaderno se destacan largas tablas descriptivas y presupuestos estimados de los elementos arquitectónicos, organizadas por capítulos y piso: techo, divisiones internas; fachadas ciegas; carpintería; equipamientos sanitarios y sistemas hidráulicos; calefacción y otros equipos eléctricos.

\subsection{Un bogotano en el proyecto de Chandigarh}

La lista de obras indianas que contaron con la participación de Samper es extensa, comenzando por los estudios urbanos generales, entre los cuales señalamos el Capitol y la Grilla de Arborización (clasificación morfológica de las especies, posibilidades de agrupación y estudios climáticos; FLC 05983). En febrero de 1953, trazó esquemas para el City Center: sector con galerías comerciales en los primeros pisos de edificios de oficinas, finalmente diseñado por arquitectos locales. Además, el colombiano contribuyó en el estudio de las líneas de transporte público urbano (autobuses), que circularían por las V2, V3 y V4, conectando la capital con el nuevo aeropuerto extra-muros y el mundo rural (FLC 05201; FLC 05277).

\subsubsection{El Capitol y sus edificios}

Además de la definición del skyline (FLC 05140), prácticamente todos los edificios previstos en la nueva explanada contaron, en mayor o menor medida, con contribución del colombiano. La serie de plantas $\mathrm{N}^{\circ} .4361$ (FLC 05141/42) ilustra un espacio público más convencional que la versión construida, con una secuencia simétrica de espejos de agua a lo largo del eje que conectaría el Palacio de Justicia con la Asamblea. Habría una torre en lugar del edificio longitudinal del Secretariado, perpendicular al eje. En una alusión a sus investigaciones sobre los volúmenes platónicos, Le Corbusier incluyó un cubo rematando la composición, correspondiente al Raj Bavhan (desarrollado posteriormente por Tobito) -que desaparecería en bocetos y collages subsecuentes, también firmados por Samper-, además de nuevas zonas verdes y alteraciones topográficas.

Samper tuvo una participación intensa para el primer esquema para la Asamblea, publicado en el volumen $\mathrm{V}$ de la Euvre Complete. Las mayores transformaciones tuvieron lugar en la forma en herradura de la "Lower House" (FLC 03103; FLC 03016). A su vez, la "Upper House", inicialmente propuesta como un hexágono flotante, replicaba al fallido Palacio de los Soviets ${ }^{10}$. Fachadas reticulares con transparencias también fueron dibujadas por el colombiano, así como secciones indicando la iluminación cenital a través de tímidas claraboyas. Tanto para éste proyecto (FLC 03324/25) como para la Alta Corte (FLC 04354; 05146A), el "León" construyó diagramas conceptuales del programa y flujo de actividades (en el segundo caso, instancias ceremoniales, residencias de visitantes y apartamento del gobernador).

Su contribución al diseño del Palacio de Justicia estuvo vinculada a una fase avanzada del proyecto, dibujando las fachadas posterior y laterales, en escala 1:100 (FLC 04521; FLC 04556/58). En ésta, el pórtico monumental de acceso, apoyado sobre tres gigantescos pilares coloridos, exhibe la nueva e intensa policromía plasmada en la paleta de colores Salubra 2, de 1959 (desarrollada con colaboración de Tobito). Samper también trazó esquemas del sistema de ventilación de los tribunales: un ducto de altura triple, que sobresale del volumen central sin irrumpir en la cubierta en "V", recapturando el aire caliente por un segundo ducto y enfriándolo con un sistema frigorífico (FLC 04764). Por último, esbozó las primeras elevaciones para el monumento de la Mano Abierta, construido en la década de los 80 y cuya relación con el paisaje himalayo ha sido ampliamente discutida- y de las rampas y escaleras hacia la Fosa de la Consideración (FLC 0583/35).

\footnotetext{
${ }^{10}$ Papillault, Rémi: Chandigarh et Le Corbusier, création d'une ville en Inde 1950-1965. Toulouse: Poḯsis, 2011.
} 


\subsubsection{Coordinando el Secretariado}

Teniendo a su cargo el trabajo de colegas como Peña o el chileno Emilio Duhart, Samper asumió la coordinación de la sede para 9 ministerios de Punjab, en septiembre de 1951, actuando como interlocutor entre "Corbu" y la firma calculista Schaud \& Metz. La cantidad de originales conservados por el arquitecto merece un estudio detallado; aquí apenas mencionamos algunas fases que contaron con su participación exhaustiva:

- Desarrollo del esquema longitudinal (sugerencia del ingeniero Thapar): una barra de $254 \mathrm{~m}$ de largo; yuxtaposición de 6 módulos estructurales y volúmenes externos para escaleras (posteriormente reemplazadas por rampas), los cuales, junto a los monumentales brise-soleils, rompieron su monotonía. Un reporte detallado del colombiano (febrero de 1952) denuncia las dificultades técnicas no sólo por causa de las dimensiones del edificio, sino por el flujo de trabajadores al interior de oficinas en doble crujía, quienes comenzarían y terminarían su jornada simultáneamente. La Grille Climatique y sus estudios solares fueron otro de los aportes definitivos del "León" al Secretariado. Tras el clima inclemente del lugar, era fundamental un sistema de ventilación natural, explicando en el "corte fundamental" transversal de un piso tipo, de $2.26 \mathrm{~m}$ de altura libre, el (FLC 02640; FLC 03435). La fachada más afectada (sureste) fue intensamente estudiada por Samper en enero de 1952, considerando cuatro pan-de-verre diferentes en el módulo intermedio del edificio (bloc n. 4, salas de ministros; FLC 02654A /B y FLC 03433).

- En junio de 1952, y con eventual colaboración de Peña (FLC 02869, FLC 02884) Samper elaboraría incontables versiones de esa elevación basada en el patrón 3.66 del Modulor, ajustando el "tejido" (como él mismo lo denominó) de los balcones brise-soleil, cuyo anclaje a la estructura principal se dificultaba por la desproporción de su voladizo. Le Corbusier ordenó dibujar columnas exentas según el ritmo de la estructura principal (en primera instancia, Samper se rehusó, sin prever la riqueza proporcionada por la superposición de ambos ritmos ${ }^{11}$ ). Posteriormente, en su cuaderno bocetó dos pérgolas de acceso (una curva, la que se construyó, y otra convencional; GS8099, GS8100) y las primeras perspectivas internas del vestíbulo, antecedido por un espacio abierto bajo el piso artificial del nivel 1. El año de 1953 sería aun más arduo, definiendo las fachadas laterales y nuevas versiones de todas las plantas, en escala 1:200, con la coparticipación de Kim (FLC 02669; FLC 02668; FLC 03404). La configuración de esas plantas aun dependía del establecimiento de los ejes estructurales por parte de los ingenieros.

Algunas perspectivas y axonometrías coloridas de Samper ilustran la calzada excavada entre al Secretariado con la Asamblea (Fig. 6). En julio, éste profundizó en la composición del club sobre el toit-jardin (FLC 02786): un prisma horizontal predominantemente de vidrio y cubierta en "V", apoyado sobre pilotis y religado a la cubierta mediante una rampa. En octubre de 1953, nuevas exploraciones en planta de ese espacio y esquemas estructurales para la loggia del Gobernador soportada mediante un sistema estructural diferente para cada una de sus tres caras, constituían las últimas contribuciones al dossier de Samper (FLC 29120A; FLC 29120C). Éste viajaría a India en 1961, constatando el fruto de su trabajo para el Secretariado, inaugurado en 1958.

\footnotetext{
${ }^{11}$ Samper, Germán: Le Corbusier de cerca. Revista Camacol, N ${ }^{\circ}$. Especial Le Corbusier 100 años, 1987, p. 63.
} 


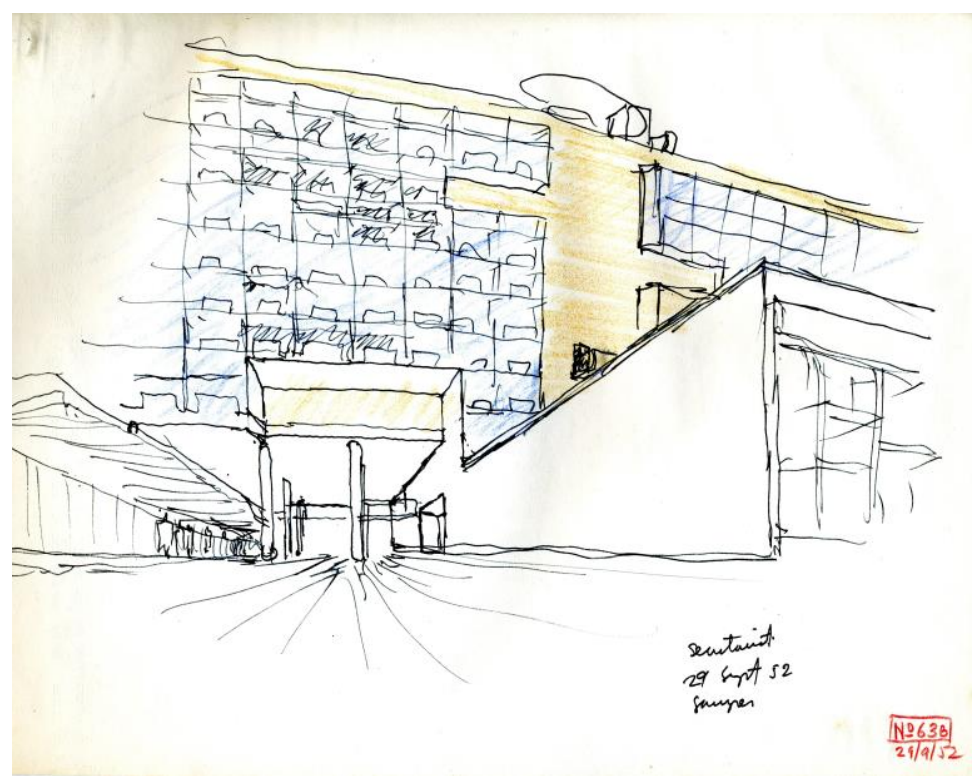

6. Perspectiva peatonal del acceso y fachada principal del Secretariado. Fuente: GS (8075).

\subsection{Regreso a Colombia}

Debido a uno de los viajes de Le Corbusier a Chandigarh, Samper no logró despedirse, dejando apenas una carta (05/11/1953). El último certificado laboral emitido para el colombiano expresa todas sus cualidades esenciales: precisión, sangre fría, orden y capacidad de invención. Días antes, "Corbu” también le regaló una famosa ilustración de una de las actitudes cotidianas ineludibles, según él, delante de la vida: como el Quijote, era necesario combatir contra molinos de viento. A su regreso a Bogotá, Samper mantuvo contacto con París, representando a Rue de Sèvres para la construcción del Banco Francés e Italiano (no desarrollado). Por su parte, el franco-suizo le expresó su deferencia al incluirlo en la lista de posibles miembros de la FLC.

\section{Augusto Tobito (Rubio, 1921 - Ginebra, 2012)}

Tobito había trabajado en Bogotá antes de llegar a Rue de Sèvres, como arquitecto y como docente en la Universidad de los Andes. También hizo parte del CIAM Colombia, según la lista registrada en su séptima versión, y participó del proyecto urbano para Tumaco, dirigido por Town Planning Associates. Como Salmona y Samper, conoció a Le Corbusier en su primer viaje a Bogotá, como miembro de la Sociedad Colombiana de Arquitectos. Los detalles de la contratación de Tobito en París serían concertados desde enero de 1953, pero su efectiva incorporación se dio dos meses después, cuando apareció sorpresivamente en el taller sin que hubiese sido expedido su permiso de trabajo. Trabajó en un número importante de proyectos (27) y entabló una relación cercana con Xenakis. Sumado a la melancolía por el fallecimiento de Yvonne Gallis en 1957, su maestro comenzaba a sentir molestia por la prolongada permanencia de los dos, lo que lo llevó a atribuirles el estatus de dattiers $^{12}$. Tobito ${ }^{13}$ narra diferencias metodológicas con relación a sus antecesores latinos: “[...] el colaborador iniciaba una solución y Le Corbusier trataba de comprender la proposición hecha e iba introduciendo ideas personales en el camino que había de seguir el proyecto [...]. También sucedía que de pronto encontrase una falla en la solución propuesta y entonces daba un giro completamente nuevo a la solución inicial o bien la

\footnotetext{
${ }^{12}$ En la última página de L'Atelier de la Recherche Patiente (Paris: Éditions Vincent Fréal, 1960) aparece: «Xénakis [sic], Tobito et Maisonnier, qui ont quitté l'atelier en 1959, ont demandé à être désignés : architectes chef d'études ».

${ }^{13}$ Tobito, Augusto: Le Corbusier: Gigante del siglo XX. Punto. №. 25, 1965, pp.19-20.
} 
transformaba paulatinamente a lo largo de las sesiones que dedicaba a esos proyectos". El propio Corbusier en carta al ministro de desarrollo iraquí, justificaría el retardo en el proyecto del estadio de Bagdad en esta nueva y más paciente manera de proceder ${ }^{14}$.

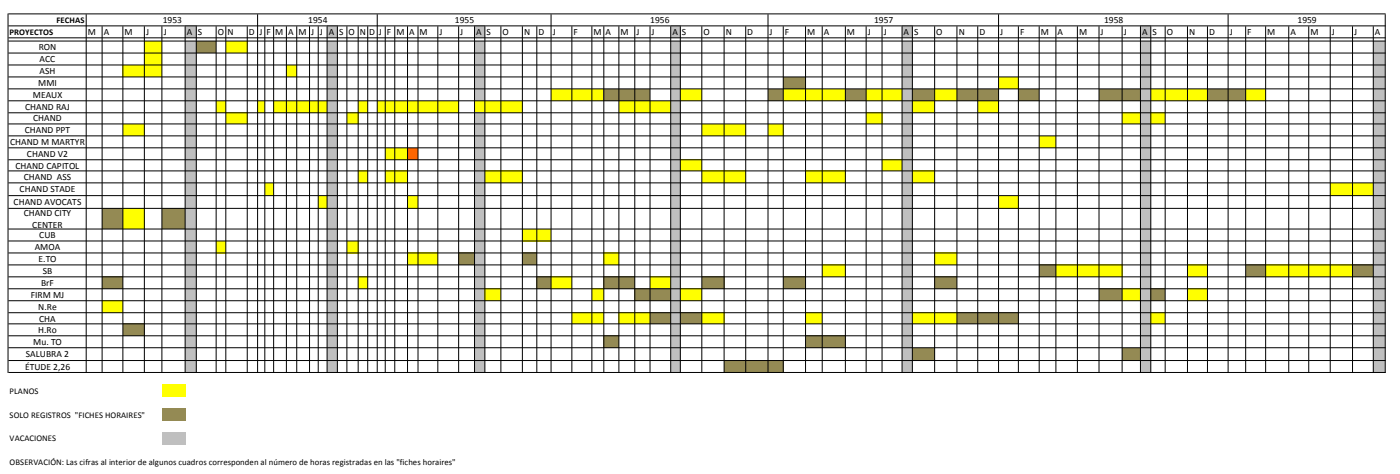

7. Tabla de proyectos lecorbusierianos con documentación relativa a Augusto Tobito. Fuente: La autora, basada en archivos de la FLC.

\subsection{Proyectos Indios y Arquitectura Simbólica}

La participación del venezolano en el atelier comenzó justo donde la de los colombianos terminaba: en propuestas para Chandigarh: Capitol; City Center y Edificio de Abogados. En éste, Tobito modificó la volumetría dibujada por Salmona, proponiendo un prisma bajo, apenas conectado a la barra principal por una galería abierta (FLC 04684/86). Para City Center, dibujó un conjunto de edificios de oficinas en altura a escala 1:100, cuyos basamentos configurarían una especie de bazar turco (FLC 05123/24). Tobito también dibujó las fachadas para el PTT Building, uno de los extraños rascacielos previstos para la capital de Punjab. Su particularidad: la inclusión de pan-de-verres ondulatoires (FLC 29138), característicos de otro proyecto en el que el dattier tuvo una participación fugaz: el convento de La Tourette (FLC 01066/69). Como reemplazo de Samper en la coordinación del Secretariado en septiembre de 1953, efectuó transformaciones importantes en la distribución de las salas de ministros (FLC 02848/49) y en la composición de sus fachadas (FLC 03517), al alternar vitrales con bloques de vidrio.

\subsubsection{Raj Bahvan}

El Palacio del Gobernador fue el único de los cuatro grandes edificios del Capitol no ejecutado. El gobernador Nehru rechazó un primer esquema debido a sus dimensiones, sobrepasando el presupuesto y oponiéndose al espíritu austero democrático. Los primeros croquis en planta del dattier denotan instancias sinuosas, dispuestas sin orden aparente (especialmente en el último nivel, donde se dispondría el apartamento principal. FLC $03896-$ FLC 04104/8) en medio del perímetro cuadrado del edificio. Éste soportaría una red estructural de pilares cruciformes (Fig. 8). Resalta una serie de siluetas que Tobito hizo con el pintoresco perfil del Raj Bahvan (FLC 04148): coronando el basarti, en el quinto nivel, se levantaría una cubierta a manera de platón, presuntamente relacionada con los motivos taurinos de la pintura lecorbusieriana. La fenestración del lado suroeste del cubo, en el segundo nivel, evoca la fachada de acceso de Ronchamp (FLC 03791), así como de la Villa Shodhan, con vitrales visibles en las secciones-fachada del salón de esa casa, también dibujadas por el venezolano (FLC 07496/97). En abril de 1955, los estudios estructurales se vieron afectados por la presión de las autoridades

\footnotetext{
${ }^{14}$ Marefat, Mina: “Mise au point for Le Corbusier’s Baghdad Stadium”. En Docomomo, No . 41, 2003, p. 36.
} 
indias, quienes retuvieron buena parte del pago. Eso desencadenó un atraso y posterior charrette $^{15}$ en junio, produciendo el primer conjunto completo de planos para el palacio (FLC 03777/84). En los cortes 3 y 4 (FLC 03801; FLC 03814), entre el cuarto y quinto piso, el dattier dibujó una especie de bóveda, también proyectada en las fachadas sureste y noreste, donde se percibe mejor su complejidad volumétrica (se incorporaba una ametralladora para la entrada de luz cenital; FLC 03811/13). Entre los últimos dibujos de Tobito para el Palacio, cuya construcción fue descartada en junio de 1957, hay secciones transversales de los brise-soleils (FLC 03823).

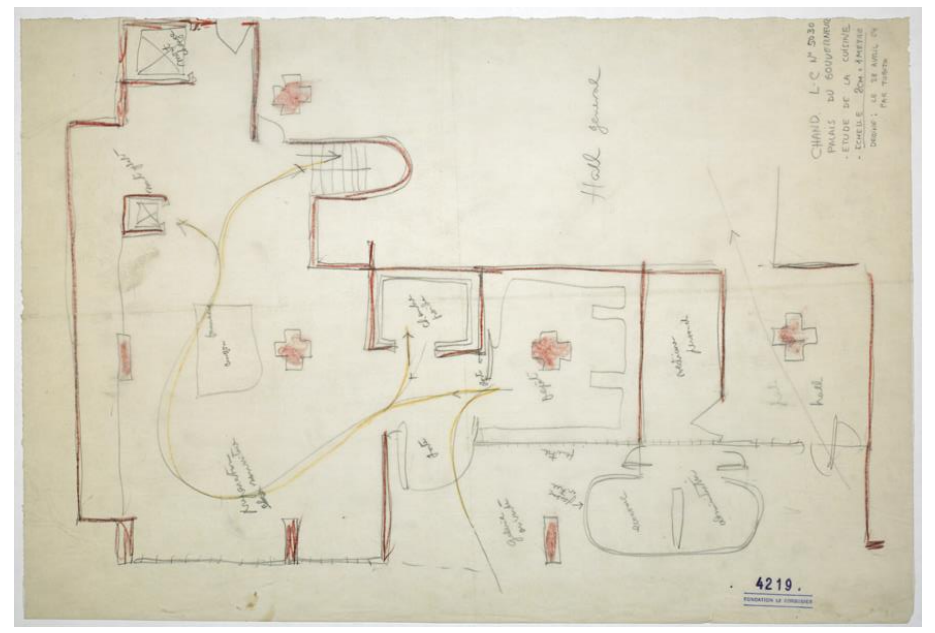

8. Esquema del hall general del Raj Bahvan, por Tobito. Fuente: FLC (04219A).

\subsubsection{Asamblea}

Luego de pasar frente a los reactores de una central nuclear en Lorraine, Le Corbusier pidió a Maisonnier y Tobito descartar los estudios de Samper para la Asamblea y desarrollar un monumental hiperboloide truncado como sala de diputados, cuya altura duplicaba la del conjunto de oficinas administrativas, en el perímetro de la propuesta (FLC 02903). Las secciones y plantas de los cinco pisos fueron elaboradas por el venezolano en septiembre de 1955, ilustrando una de las alas de la Asamblea nacida del nivel excavado y vinculada al acceso vehicular por piso abierto, con pilotis, rampas y algunos cubículos (FLC 02965). El acceso ceremonial se daría por la fachada oriental, luego de franquear la pasarela sobre el espejo de agua. Esbeltas columnas rodearían la hipérbole en la sala de pasos perdidos. La planta de la cubierta, también elaborada por Tobito, exhibe la proyección de la claraboya para la sala principal, cuya distribución interna, en escala 1:100, redibujó en marzo de 1957 (FLC 02929). En octubre, el venezolano trazó las cuatro fachadas del edificio: la oriental ostentaba una pérgola de acceso distinta a la construida, no curva sino oblicua (FLC 03034). Junto a Xenakis, también construyó una maqueta en la que incluye la pirámide en la terraza-jardín. Cerrando la producción del venezolano, una versión definitiva de esa planta (FLC 03089) ilustra las nervaduras de la nueva pérgola.

\subsection{Repensando las unidades habitacionales}

El dattier tuvo una participación fugaz en los dossiers de algunas unités como Rezé-les-Nantes, dibujando una perspectiva sur de la unidad, con un lago en primer plano (FLC 02316A/B). Una plancha idéntica, marcada con nomenclatura de Briey-en-Forêt (FLC 17327), fue firmada por él, junto a otros 13 dibujos en enero de 1956:

\footnotetext{
${ }^{15}$ Jerga francesa comúnmente usada en el taller para designar un momento de presión extrema en su producción.
} 
fachadas del edificio (FLC 30434A/B) y de la terraza-jardín (FLC 17335) la cual finalmente carecía de los componentes de sus antecesoras.

\subsubsection{Meaux o la multiplicación de unités}

Paralelamente al desarrollo de Rezé, Le Corbusier asumió un estudio para 2000 viviendas en un suburbio industrial al oriente parisino, promovido por la compañía Renault. Éste complementaría la Fábrica Verde propuesta por el maestro del otro lado de la autopista nacional $\mathrm{N}^{0}$. 3. Tobito dibujó los primeros esquemas de implantación, con cinco unidades idénticas e inmuebles à redent para equipamientos (FLC 21560). Como en Estrasburgo, dos torres cilíndricas alojarían solteros. En los meses sucesivos, consideró más posibilidades de organización del sector a partir de los mismos elementos, presentadas mediante una grilla CIAM en febrero de 1956 (FLC M3-12-488).

Ante el rechazo de la propuesta por parte de sus clientes, "Corbu" planteó una intervención mayor, abarcando parte del rio La Marne; creando una zona de explotación agrícola y considerando 20 unidades para aumentar la densidad del centro urbano (FLC 21568). Posteriormente, Tobito desarrolló un esquema de tan sólo 17 unités (FLC 21690); una tercera alternativa, de marzo, reduciría su número a 8 (FLC 21730). Para subsanar las viviendas faltantes, se proponían barras sinuosas, evocando el proyecto lecorbusieriano para Alger (1930). La siguiente versión de Meaux sólo contaría con 800 habitaciones, entre células y casas Rez-de-Chaussée, organizadas por una trama urbana diagonal delimitada por una carretera perimetral. El dattier se concentró en el estudio de la zona industrial (norte), deslindada por una vía férrea (FLC 21888A/B/C). En noviembre de 1955, detalló las plantas de las unidades (FLC 21443; FLC 21894), simplificando la estructura de las unités precedentes, con cuatro y no tres mega-pórticos en el sentido transversal ${ }^{16}$. Dos planos simples, inclinados, convergirían en cada pilar en "V". La posibilidad de construcción serializada de unidades gestó un equipo técnico al interior de Rue de Sèvres, el EQUIPBA (Équipe de Bâtisse), liderado por Xenakis, con participación eventual de Tobito y Maisonnier, investigando el montaje en seco de células. Se convocó a la Renault para formular el Sistema Meaux, de principio cercano al Brevet, combinando concreto armado en los nudos de amarre, plástico y acero. Ante la presión de la automotriz para su comercialización, el maestro abandonó la idea. Antes, Xenakis y Tobito desarrollaron estudios comparativos entre las diferentes unidades, derivados en módulos cúbicos de $2.26 \mathrm{~m}$ para Meaux (carpeta FLC M3-4). También se plantearon viviendas de baja altura bajo el mismo patrón, suscitando propuestas morfológicamente complejas, que quedaron abandonadas como el resto del proyecto, en el verano de 1960.

\subsubsection{Unidad Typ-Berlin}

La unidad berlinesa nació de la invitación a Le Corbusier para participar en la Interbau, exposición de arquitectura moderna. Inicialmente de 400 células (aumentadas posteriormente a 557) ésta no se construiría en Hansaviertel, barrio de la muestra, sino en Charlottenburg, al oeste de Berlín. Tobito se encargó de estudiar la implantación de la propuesta, al adaptar a la topografía y trazado original del terreno mediante la creación de una plataforma curva y semienterrada, con estacionamientos y cuartos de máquinas (FLC 23683). Los cortes generales de la unidad dibujados por el venezolano corresponden a muros estructurales similares a los propuestos para la unidad de Briey, transformados en pilares en " $\mathrm{V}$ " al contacto con el terreno (FLC 23689 A/B). En septiembre y octubre de 1956, Tobito también contribuyó con sus estudios para la guardería en el toit-jardin,

\footnotetext{
${ }^{16}$ Calafell, Eduard: Les unités d'habitation de Le Corbusier: aspectos formales y constructivos. Barcelona: Fundación Caja de Arquitectos, 2000.
} 
cuyo patio de recreo se instalaría justo por encima del volumen de aulas (no construido por cuestiones presupuestales; FLC 23685A/B). También esbozó la caja de ascensores, colinas artificiales, y un anfiteatro al aire libre (FLC 23694A/B). Los problemas comenzaron cuando las autoridades rechazaron la medida básica de $2.26 \mathrm{~m}$, exigiendo $2.5 \mathrm{~m}$ como altura mínima libre, lo que implicó ajustes del prototipo, buscando su armonía con el Modulor. La confrontación entre París y Berlín no se hizo esperar, tras modificaciones arbitrarias en obra, denunciadas en el volumen VI de la Euvre Complète ${ }^{17}$.

\subsection{Cultivar el Cuerpo y el Espíritu}

Concomitantemente a las iniciativas culturales de postguerra lanzadas por el gobierno francés, se encontraba una red de casas culturales: en Firminy, ésta fue encargada a Le Corbusier (1953). Con la alteración posterior del programa por parte del alcalde Petit, la propuesta fue integrada a un proyecto más ambicioso, con instalaciones deportivas, consolidando la cuarta función de la ciudad moderna: cultivo del cuerpo y del espíritu. Finalmente denominada como la Casa de la Juventud, la barra de 112 metros de largo, separada del estadio por taludes, fue laboratorio de un nuevo lenguaje técnico y formal. Contó con participación casi autónoma de Tobito y Xenakis en lo referente al estudio en sección de la cubierta inclinada (FLC 16826; la versión definitiva denota una curva invertida), cuya semejanza con la Escuela Júlia Kubitschek en Diamantina (Brasil), construida por Oscar Niemeyer en 1954, es indiscutible. De hecho, en el último volumen de su Euvre Complète ${ }^{18}$, Le Corbusier acusó sutilmente a sus colaboradores de propiciar un supuesto plagio.

\subsubsection{La crisis de Bagdad y el ocaso de los dattiers}

Tobito y Xenakis trabajaron mancomunada e intensamente en la solución estructural del Estadio de Bagdad, entre abril y julio de 1958, continuando las investigaciones técnicas y funcionales de Firminy. El estadio de planta circular albergaría 50000 espectadores y una pista olímpica, además de algunas excentricidades "a la romana" como una fosa para festivales y cuatro vomitoriums (FLC 00166). Ambos dattiers elaboraron estudios comparativos de equipamientos deportivos en otras capitales y, en abril de 1958, comenzaron a dibujar elevaciones de más de 20 tipos de contrafuertes de concreto (FLC 29507): pantallas (voiles) de hasta 3 pisos de altura $(8 \mathrm{~m})$ dispuestas radialmente en todo el perímetro del estadio. La dupla también esbozó el palco cubierto para el rey: un volumen cúbico, aislado, a media altura de las graderías (FLC 29519-22; FLC 29526). En junio de ese año, Tobito dibujó en solitario todo el complejo, "en limpio", así como circulaciones verticales dentro del equipamiento y una plataforma para periodistas y vestuarios, coincidiendo con las tres líneas más bajas de graderías (las líneas superiores aparecen en voladizo; FLC 00250). La solución de la cubierta, en concreto armado, tensores de acero y lonas plásticas, fue formulada por el ingeniero Georges Presenté ${ }^{19}$, quien terminaría de desarrollar el proyecto, ejecutado póstumamente.

\subsection{Entre los fieles}

Desde marzo de 1959, "Corbu" contemplaba el despido de sus dattiers, tras la exigencia de un aumento de salario. Una nota genérica anunció su retiro cinco meses después; justificado por la necesidad de darles alas para

\footnotetext{
${ }^{17}$ Boesiger, Willy (Ed.): Le Corbusier et son atelier rue de Sèvres 35. CEuvre Complète 1952-1957. Zürich: Les Éditions d'Architecture, 1957. v6, p. 192.

${ }_{18}$ Boesiger, Willy (Ed.): Le Corbusier et son atelier rue de Sèvres 35. Euvre Complète 1957-1965. Les Éditions d'Architecture. Zürich: 1966. v7.

${ }^{19}$ Ragot, Gilles: Le Corbusier à Firminy-Vert, manifeste pour un urbanisme moderne. Paris: Éditions du Patrimoine-Centre des monuments nationaux, 2011, p. 136.
} 
volar por sí mismos ${ }^{20}$, y por diferencias de opinión respecto a la forma general y rampas externas del estadio de Bagdad $^{21}$. Un mes antes, el maestro había solicitado a su contador la liquidación para los tres colaboradores. El venezolano apenas regresaría a su país en noviembre de ese año, para ejercer como docente de la Universidad Central en Caracas. El día 5 de ese mes, Le Corbusier le había regalado un dibujo de su autoría, con la nota "“...] merci de votre gentillesse naturelle ${ }^{, 22}$. Poco antes de su fallecimiento, en julio de 1965, el maestro recibió en su apartamento una visita del venezolano: «J'étais heureux de revoir Tobito, qu'il poursuivait, qu'il était parmi les fidèles. Lorsque nous nous sommes quittés [...], j’ai dit à Tobito que qui pensait revenir me voir l'année prochaine $»^{23}$. En retorno a su gentil despedida, el dattier ${ }^{24}$ escribió con motivo de la muerte del maestro: “ $A U d$. El Hombre cabal, en postrer homenaje, con el adiós de los amigos: ¡Adiós, monsieur Le Corbusier!’.

\section{Conclusiones}

De entre los andinos, quizás por su juventud, desinterés o brevedad de la pasantía, ni Salmona, ni Valencia ni Peña parecen haber incidido en las adaptaciones metodológicas del taller. No obstante, el papel del primero, como articulador entre empleados más recientes y la lógica proyectual del maestro, es innegable, evidenciado por la cantidad de proyectos en los que participó y perspectivas que dibujó. Transformaciones en las herramientas proyectuales (collages, diagramas de flujos, dibujos ingenuos y coloridos), tradicionalmente vinculadas a la llegada del chileno Guillermo Jullian al taller, se vislumbran en la abundante documentación aportada por Samper, particularmente en los relacionados al proyecto del Secretariado. Por otra parte, la mayoría de los proyectos lecorbusierianos que contaron con la contribución de latinoamericanos están ligados con la vivienda masiva y su papel en los nuevos planes urbanos: incluso temas como la nueva policromía (explorada desde la fachada de Marsella); el apelo constante a los patrones del Modulor; el uso recurrente de los vitrales; la creación de formas alegóricas del universo pictórico lecorbusieriano y su diálogo a diferentes escalas con la geografía circundante, abordadas en mayor o menor medida por los dattiers, contribuyeron a la creación de ese espacio inefable, consolidado en Chandigarh con antecedencia a la llegada de Jullian. Se eximía así la indispensable presencia de obras artísticas de diferente índole, lo que Le Corbusier dejó entrever al definir" ${ }^{25}$ : " $L a$ quatrième dimension semble être le moment d'évasion illimitée provoquée par une consonance exceptionnelle juste des moyens plastiques mis en ouvre et par eux déclenchée. [...] une victoire de proportionnement [sic] en toutes choses - physique de l'ouvrage comme aussi efficience des intentions contrôlées ou non, saisies ou insaisissables, existantes toutefois et redevables à l'intuition [...] Alors une profondeur sans bornes s'ouvre, efface les murs, chasse les présences contingentes, accomplit le miracle de l'espace indicible [...] couronnement de l'émotion plastique".

La Búsqueda Paciente, llena de incertidumbres, sólo se detuvo con la muerte de "Corbu", aquel verano de 1965. En contraste con el efímero paso de otros colaboradores latinos por el taller, estos dattiers aprehendieron del maestro esa virtud, en aras de explorar una idea hasta sus últimas consecuencias (caso Secretariado y la contribución de Samper), incluso si la esperanza de materializar dicha búsqueda era casi nula (caso Meaux y la intervención de Tobito). Su resistencia efectiva, sólo se dio en la propia acción profesionales de estos personajes

\footnotetext{
${ }^{20}$ Carnet IV (28 août 1959). De Franclieu, Françoise (Ed.): Le Corbusier: Sketchbooks. New York, Cambridge: MIT Press, $1981.5 \mathrm{v}$.

${ }^{21}$ Loach, Judi: L'Atelier LC, un centre européen d'échanges. Monuments Historiques, v. III-IV, No. 180. 1992, p. 76.

${ }^{22}$ Archivo personal Bárbara Bradley.

${ }^{23}$ Boesiger, Willy (Ed.): Le Corbusier: Les dernières Euvres. Zürich: Artemis, 1969. pp. 168-169.

${ }^{24}$ Tobito, Augusto: Le Corbusier: Gigante del siglo XX. Punto. $\mathrm{N}^{\mathrm{o}} .25,1965, \mathrm{p} .11$.

${ }^{25}$ Le Corbusier: L'espace indicible. L'Architecture d'Aujourd'hui, $\mathrm{N}^{\mathrm{o}}$. hors série, 1945.
} 
en sus lugares de origen: Salmona como principal exponente de la arquitectura del ladrillo; Samper como edificador de miles de casas de crecimiento progresivo y autoconstrucción por parte de las propias comunidades obreras; Tobito como docente reformista y experto en asuntos bioclimáticos.

\section{Referencias bibliográficas}

Arcila, Claudia Antonia: Tríptico Rojo. Conversaciones con Rogelio Salmona. Bogotá: Taurus, 2007.

Boesiger, Willy (Ed.). Le Corbusier et son atelier rue de Sèvres 35. Cuvre Complète 1952-1957. Zürich: Les Éditions d'Architecture, 1957. v6.

Boesiger, Willy (Ed.): Le Corbusier et son atelier rue de Sèvres 35. CEuvre Complète 1957-1965. Les Éditions d'Architecture. Zürich: [s.n.], 1966. v7.

Boesiger, Willy (Ed.): Le Corbusier: Les Dernières Euvres. Zürich: Artemis, 1969.

Calafell, Eduard: Les unités d'habitation de Le Corbusier: aspectos formales y constructivos. Barcelona: Fundación Caja de Arquitectos, 2000.

De Franclieu, Françoise (Ed.): Le Corbusier: Sketchbooks. New York, Cambridge: MIT Press, 1981. 5v.

Le Corbusier: L'Atelier de la Recherche Patiente. Paris: Éditions Vincent Fréal, 1960.

Le Corbusier: "L’espace indicible". En L'Architecture d'Aujourd'hui, $\mathrm{N}^{\mathrm{o}}$. hors série, 1945.

Le Corbusier: Plans. Paris: CodexImages International, Fondation Le Corbusier, 2005.

Loach, Judi: "L'Atelier LC, un centre européen d'échanges". En Monuments Historiques, v. III-IV, Nº 180. 1992 ,

Marefat, Mina: Mise au point for Le Corbusier’s Baghdad Stadium. En Docomomo, No . 41, 2003.

Papillault, Rémi: Chandigarh et Le Corbusier, création d'une ville en Inde 1950-1965. Toulouse: Poïésis, 2011,

Samper, Germán: "Le Corbusier de cerca". Revista Camacol, N . Especial Le Corbusier 100 años, 1987.

Sterken, Sven: Iannis Xenakis: architecte et ingénieur. Dirección: Bart Verschaffel. Tesis doctoral. Universiteit Gent, 2004.

Tarchópulos, Doris: Las Huellas del Plan para Bogotá de Le Corbusier, Sert y Wiener. Dirección: Joaquín Sabaté, José María Ezquiaga. Tesis doctoral. Universitat Politécnica de Catalunya, 2010.

Tobito, Augusto: "Le Corbusier: Gigante del siglo XX". En Punto, No. 25, 1965. 